\title{
A Study on Outcome of Early Caffeine Administration in Very Preterm Neonates
}

\author{
${ }^{1}$ Basavaraj, ${ }^{1}$ Hareesh Sanikam, ${ }^{2}$ Pavan Pujar, ${ }^{3}$ Anjali R, ${ }^{4}$ Pushpalatha K \\ ${ }^{1}$ Assistant Professor, Department of Paediatrics, ESIC MC \& PGIMSR, Rajaji Nagar, Bengaluru, 2'Junior Resident, Department of Paediatrics, ESIC MC \& PGIMSR, Rajaji \\ Nagar, Bengaluru, ${ }^{3}$ Neonatologist, Department of Paediatrics, ESIC MC \& PGIMSR, Rajaji Nagar, Bengaluru, ${ }^{4}$ Professor \& HOD, Department of Paediatrics, ESIC MC \& \\ PGIMSR, Rajaji Nagar, Bengaluru.
}

\section{Abstract}

Background: Apnea intervals frequently occur in very preterm infants. Methylxanthenes stimulate breathing efforts and hence have been used for treating apnea of prematurity. Aim: to study the outcome of early caffeine administration in very preterm neonates. Subjects and Methods: The first (1st) group babies received early caffeine within 48 hours of life before developing apnea. The second group (2nd) group babies received caffeine late after 48 hours, after onset of apneic episode. Results: There was no significant difference in the number of episodes of apnea, bradycardia and hypoxemia. Also no significant difference in the incidence of Patent ductus arteriosus (PDA), Intra ventricular hemorrhage (IVH), Necrotizing enterocolitis (NEC), Retinopathy of prematurity (ROP) or Bronchopulmonary dysplsia (BPD). Conclusion: There was no significant difference noted in the number of episodes of apnea, bradycardia and hypoxemia in the group with early caffeine administratration compared to late caffeine administration.

Keywords: Caffein, Very Preterm, Apnea, hypoxemia, bradycardia.

Corresponding Author: Dr. Hareesh Sanikam, Assistant Professor, Department of Paediatrics, ESIC MC \& PGIMSR, Rajaji Nagar, Bengaluru.

Received: April 2019

Accepted: April 2019

\section{Introduction}

Apnea intervals frequently occur in preterm infants. ${ }^{[1,2]}$ The American Academy of Pediatrics describes apnea as a cessation of breathing for 20 seconds or longer or a shorter pause accompanied by bradycardia ( $<100$ beats per minute), cyanosis, or pallor. ${ }^{[3]}$ Periods of apnea occur more often with decrease in gestational age. ${ }^{[4]}$ In an observational study, it was reported that the incidence of recurrent apnea increased with decreasing gestational age. Essentially, all infants born at $\leq 28$ weeks gestation were diagnosed with apnea; beyond 28 weeks gestation, the proportion of infants with apnea decrease, from $85 \%$ of infants born at 30 weeks gestation to $20 \%$ of those born at 34 weeks gestation. ${ }^{[5]}$ Despite the fact that apnea can occur solely because of the prematurity of the infant, certain situations such as hypoxic periods, metabolic disorders, intracranial pathologies, and infections can also trigger apnea.

Periods of apnea can cause damage to the infant's developing brain, and also disrupt the function of the intestine and other organs. ${ }^{[4]}$ Recurrent and prolonged intervals of apnea can result in respiratory failure, making intubation and ventilation mandatory. Methylxanthenes stimulate breathing efforts and therefore, they have long been used for treating apnea of prematurity. ${ }^{[6]}$ They also decrease the need for mechanical ventilation. Although the mechanism of action is not yet clearly known, optimization of the response of chemoreceptors to Partial Pressure of Carbon Dioxde (pCO2) rise, improvement in the function of respiratory muscles, and central nervous system stimulation have been noted. ${ }^{[1]}$

Two commonly available forms of methylxanthenes are theophylline and caffeine. Compared with the former, caffeine has more certain intestinal absorption, a wider therapeutic index, and a longer half-life, which makes it possible to be administered daily once. ${ }^{[6]}$ The prevention of apnea and hypoxic intervals avoids the side effects of using oxygen, intubation and related complications. Use of caffeine for the treatment of apnea in preterm babies is well established. There is paucity of data on prophylactic (early) use of caffeine for apnea in preterm babies. Hence present study was undertaken to know the effectiveness of prophylactic (early) caffeine in preventing episodes of apnea, bradycardia and hypoxemia in preterm babies.

\section{Subjects and Methods}

Source of data: Preterm newborns admitted to NICU, ESIC MC \& PGMSR, Rajajinagar, Bengaluru from September, 2017 to September, 2018. The study was approved by the 
Institutional Ethics committee, and written informed parental consent was obtained for each participating infant. Inclusion criteria included newborn infants $\leq 32$ weeks of gestation and/or birth weight $<1250$ grams. Exclusion criteria included, babies with major congenital anomalies and babies with cyanotic congenial heart disease.

All preterm infants meeting inclusion criteria were included in the study. Babies were randomly allocated into two groups. The first (1st) group received prophylactic (early) caffeine within 48 hours of life. The second group (2nd) babies received caffeine late (day 3 or greater). Both groups were studied for common baseline parameters. Primary outcome measures like frequency of apnea, bradycardia, and episodes of hypoxemia and requirement of CPAP or ventilator support were studied in both the groups. Effect of caffeine therapy on preterm neonatal complications like IVH, NEC, PDA and BPD were evaluated and compared between two groups.

Randomization was done using computer generated randomization list prepared by an independent statistician who was not involved in the rest of the investigation. The numeric data was expressed as Mean whereas, non-numeric data as frequencies and percentages. Comparison between two groups was done by using Chi-square test for significance. $\mathrm{P}$ value less than 0.05 was considered as statistically significant.

\section{Results}

During the study period of 12 months, 52 neonates meeting the inclusion criteria were included in the study and were randomized into 2 groups. The mean gestational age in 1st and 2nd group was 30.8 weeks and 31 .1weeks respectively. The mean birth weight was1142.7 grams and 1116.2grams in 1st and 2nd groups respectively. Baseline characteristics were similar in both the groups. [Table 1]

\begin{tabular}{l}
\hline Table 1: Baseline characteristics of babies. \\
\begin{tabular}{|l|l|l|}
\hline Characteristics & 1st group N=26 & 2nd group N=26 \\
\hline In-Born & $26(100 \%)$ & $26(100 \%)$ \\
\hline Females & $10(38.4 \%)$ & $9(34.6 \%)$ \\
\hline Born by LSCS & $15(57.7 \%)$ & $13(50 \%)$ \\
\hline $\begin{array}{l}\text { Birth Weight in grams } \\
\text { (mean) }\end{array}$ & 1116.2 & 1142.7 \\
\hline $\begin{array}{l}\text { Mean gestational } \\
\text { age(Weeks) }\end{array}$ & 30.8 & 31.1 \\
\hline
\end{tabular}
\end{tabular}

The mean day of administration of caffeine in 1st group was 1.88 days and and in 2 nd group was 4.27 days.

There was no significant difference in number of apnea episodes in both the groups (mean number of apneic episodes was 1.76 and 1.65 respectively in 1 st and 2 nd group and p-value of 0.27 ). The mean number of episodes of bradycardia was 2.23and 2.38 in each group respectively and the mean episodes of hypoxemia was 2.5 and 2.53 in each group respectively.
There was also no significant difference in the number of episodes of bradycardia and hypoxemia in both the groups (p-values-0.22 and 0.15 respectively). There was no significant difference noted in the primary outcomes.

The mean days on CPAP was 2.6 days in 1st group and 2.1days in 2nd group which was statistically insignificant (p-value-0.74). The mean days of ventilation was 0.85 days and 1.23 days in 1 st and 2 nd groups respectively which was statistically insignificant (p-value-0.86).

The number of days hospital stay was more in the 1st group. This could be due to other co-morbidities present in babies. The mean hospital stay was 34.34 days and 32.5 days in $1 \mathrm{st}$ and 2 nd groups respectively ( $\mathrm{p}$ value-0.34) (table 2 )

Table 2: Measurements of primary outcomes

\begin{tabular}{|l|l|l|l|}
\hline Characteristics (mean) & $\begin{array}{l}\text { 1st group } \\
\text { N=26 }\end{array}$ & $\begin{array}{l}\text { 2nd group } \\
\text { N=26 }\end{array}$ & p-value \\
\hline Episodes of apnea & 1.769 & 1.653 & 0.272 \\
\hline Episodes of bradycardia & 2.232 & 2.384 & 0.224 \\
\hline Episodes of hypoxemia & 2.5 & 2.538 & 0.158 \\
\hline No of days on CPAP & 2.615 & 2.115 & 0.743 \\
\hline No of days on Ventilator & 0.846 & 1.230 & 0.864 \\
\hline $\begin{array}{l}\text { Duration of hospital stay } \\
\text { (days) }\end{array}$ & 34.346 & 32.5 & 0.346 \\
\hline
\end{tabular}

There were 4 (15.38\%) neonates in 1st group and 5(19.2\%) neonates in 2nd group with Patent Ductus Arteriosus (PDA). $26.9 \%(7 / 26)$ neonates in first group developed Necrotizing enterocolitis (NEC) as compared to $19.2 \%(5 / 26)$ in second group.

$15.38 \%$ babies in 1st group had Retinopathy of Prematurity (ROP) whereas $23 \%$ babies in second group had ROP. Bronchopulmonary dysplasia (BPD) was seen in $15.38 \%$ $(4 / 26)$ babies in both the groups. The difference was not significant. (Table 3)

No side effects were noted in both the groups.

Table 3: Secondary outcomes measurement

\begin{tabular}{|l|l|l|l|}
\hline Characteristics & 1st group N=26 & 2nd group N=26 & P value \\
\hline PDA & $4(15.38 \%)$ & $5(19.2 \%)$ & 0.5 \\
\hline IVH & $7(26.9 \%)$ & $5(19.2 \%)$ & 0.7 \\
\hline NEC & $7(26.9 \%)$ & $5(19.2 \%)$ & 0.7 \\
\hline ROP & $4(15.38 \%)$ & $6(23 \%)$ & 0.36 \\
\hline BPD & $4(15.38 \%)$ & $4(15.38 \%)$ & 0.6 \\
\hline
\end{tabular}

\section{Discussion}

In the present study, no significant difference was noted in the number of episodes of apnea, bradycardia and hypoxemia in the group with prophylactic (early) caffeine administration as compared to the group with late caffeine administration.

There was also no significant differences in the incidence of PDA, IVH, NEC, ROP or BPD in both the groups.

A study done in Iran by Amir Mohammad Armanian and Nima Salehimehr, has shown that incidence of apnea was less in babies who received prophylactic caffeine compared 
to babies who did not receive. The difference was statistically significant $(\mathrm{P}<0.001)$. There was also significant difference in incidence of cyanosis and bradycardia among the two groups. However there was no significant difference in the incidence of IVH, PDA and NEC between two groups. ${ }^{[7]}$

In a study done by Lodha A,et al., it was noted that, rates of BPD, PDA and severe neurologic injury were lower in the early caffeine group than in the late caffeine group. ${ }^{[8]}$

In a Cochrane database review, it was found that, there were no significant differences between the early and late caffeine groups in the number of infants with apnea, bradycardia, hypoxemic episode, use of IPPV(intermittent positive pressure ventilation), or side effects. ${ }^{[1]}$

Ivan Hand et al., in their study, did not observe any statistical difference in the neonatal outcomes of infants between the early and late caffeine group. However, when they compared the outcomes of early caffeine with that of the very late caffeine group ( $\geq 8 \mathrm{DOL}$ ), their analysis showed that the very late caffeine group had higher incidence of $\mathrm{BPD}$ and PDA requiring ligation. ${ }^{[9]}$

In a meta-analysis study done by Kua KP, et al., early caffeine therapy showed decreased risk of PDA, ROP, BPD and postnatal steroid use. ${ }^{[10]}$

Amaro CM,et al. conducted a study on early caffeine therapy and weaning from mechanical ventilation in preterm infants. In their study, it was found that, early caffeine therapy did not reduce the age of first successful extubation in preterm infants receiving mechanical ventilation. Also they found that, duration of supplemental oxygen and incidence of BPD was not reduced with early caffeine therapy. ${ }^{[11]}$

\section{Conclusion}

Copyright: () the author(s), 2019. It is an open-access article distributed under the terms of the Creative Commons Attribution License (CC BY 4.0), which permits authors to retain ownership of the copyright for their content, and allow anyone to download, reuse, reprint, modify, distribute and/or copy the content as long as the original authors and source are cited.

How to cite this article: Basavaraj, Sanikam H, Pujar P, Anjali R, Pushpalatha K. A Study on Outcome of Early Caffeine Administration in Very Preterm Neonates. Asian J. Clin. Pediatr. Neonatol.2019;7(2):6-8.

DOI: dx.doi.org/10.21276/ajcpn.2019.7.2.2

Source of Support: Nil, Conflict of Interest: None declared. 